\title{
Virtual Inertia Emulation in a Hybrid Micro Grid Based on Diesel Generator and Wind Power Plant
}

\author{
Aehtsham Ul Haq ${ }^{1}$, Iatizaz Ahsan ${ }^{2}$, Shazmina Jamil ${ }^{3}$ \\ ${ }^{1,2,3}$ Department of Electrical Energy System Engineering, US-Pakistan Center for Advanced Studies in Energy \\ (US-PCASE), UET Peshawar \\ shami0001@ outlook.com¹, iatizazahsan1@gmail.com², shazminajamil@yahoo.com³ \\ Received: 28 December ${ }^{2020}$, Revised: 09 January, Accepted: 17 January
}

\begin{abstract}
Micro-grids with high renewable penetration have low inertia and it leads to frequency stability problems. Virtual inertia emulation provides active power to system during transient time to improve dynamics frequency stability. In this study, derivative technique is used to calculate the derivative of frequency for virtual inertia emulation. Simulations results confirm that frequency dip occurs in case of contingency and virtual inertia control reduces this frequency deviation. It helps to improve overall frequency stability and prevents unnecessary load shedding.
\end{abstract}

Keywords - Power System Stability, Micro-grids, Renewable Energy Sources, Frequency Control, Virtual Inertia.

\section{INTRODUCTION}

Envirnmental concerns, energy policies and giving access to electricity in remote areas have encouraged distributed generation and increasing penetration of RES in power system [1]. Distributed generation introduced a new concept of a small-scale power system known as micro grid. A micro grid is a group of power grids with RES sources and loads, and it can be identified as an independent system [2]. The concept of micro grid has played a vital role in the development of electricity market. However, it reduced the inertia of the system due small size, inverter/converter based technology of RES, and led to frequency stability issues [3]. Power system based on synchronous generators follows the frequency regulations. Inertial response, primary frequency control and automatic generation control attenuate the system dynamics and decrease frequency deviation of the system, so that system instability, cascaded outages and blackout can be avoided [4]. Thus, the main concern about the safe operation and control of today's and future micro-grid is its dynamic stability as system inertia is decreasing due to increasing penetration of RES.

A novel technique known as virtual inertia emulation address these stability issues. Virtual inertia is a combination of control algorithm, power electronics circuits, energy sources and energy storage systems, which emulates the inertial behavior of synchronous generator in RES, based micro-grid
[5]. Several studies of virtual inertia emulation have discussed in the literature. Bryant et al [6] described the challenges of frequency control in Australian's power system due to increasing share of renewable power generation. Obaid et al [7] described challenges and new methods to control frequency of future power system. The virtual inertia injection in multiple PV systems of autonomous micro grid is discussed in [8]. Unlike synchronous and wind turbine, solar photovoltaic system does not possess any type of kinetic energy and it does not injects any inertial property in power system. DC link capacitor's voltage is adjusted to add virtual inertia and it injects or absorbs power when frequency changes occur. Kerdphol et al [9] proposes a new technique, which simultaneously injects the virtual inertia and virtual damping in a micro grid using derivative frequency approach. A virtual inertia control technique, VISMA or VSG is applied to imitate the virtual inertia and virtual damping in RE generating sources, which is the dynamic behavior of synchronous generator. In [10], frequency dynamics of hydropower system are modeled which helps to injection of virtual inertia. In [11], all techniques which are used virtual inertia emulation in micro grid are discussed and compared. Novel approaches are applied and proposed to inject inertial response in both voltage source and current source inverter. Bevrani et al [12] describes application of virtual inertia in frequency control of power grid. In this paper, the dynamics of the frequency deviations caused by parallel operation of the grid and VSG are analyzed, and the stabilization effects provided by VSGs are confirmed. In [13], optimization of emulated inertia is discussed. It is important to explore that where to place this inertia optimally as it is considered that placement of inertia has significant impact on power system performance. Some global as well as local optimal solution of virtual inertia problems are presented in [13].

This paper presents the $\frac{d f}{d t}$ technique of virtual inertia emulation. Virtual inertia power is calculated based on ROCOF of the system. VI loop helps to maintain the frequency stability of the micro-grid based on conventional and RES generating units during transient time. The reminder part of this paper is arranged as; Section II explains the modeling of micro-grid, 
occurance of contingency and design of virtual ineria loop. Section IV shows the behavior of frequency with and without virtual inertia emulation. Finally, conclusion are presented in section $\mathrm{V}$.

\section{MethodOlOGY}

The methodology include simulations of micro grid in MATLAB/SIMULINK, injection of a perturbation on micro grid and its analysis, emulation of virtual inertia loop on perturbed system and its analysis.

\section{A. Modeling of Micro Grid}

To access the system having shares of conventional power sources and RES, a model of micro-grid based on diesel generator and wind power plant is designed on MATLAB/Simulink. The connection of grid side inverter of wind turbine with diesel through transformer and filter $L$ is similar with simple integration of inverter with grid. The voltage and current are measured at the point of common coupling, which are transformed from a,b,c sequence to d,q,0 sequence. PLL is used to measure frequency and phase angle.

The measured value of three-phase voltage and current are sent into the power calculations block to measure the instantaneous value of active and reactive power. These measured values are compared with the $P_{\text {,ref }}$ and $Q$,ref and sent it to PI controller. PI calculates error between measured value and desired values and tries to minimize it. The control of active and reactive power is called outer control loop and its purpose to generate a reference $d q$ sequence $\left(I_{d, r e f}\right.$ and $\left.I_{q, r e f}\right)$ current. These reference $d q$ currents are sent to the inner loop that is called current control loop where measured $d q$ currents are compared with these reference currents and error is minimized by PI controller. The reference output voltage must be equal to the voltage and frequency at PCC. This reference voltage is sent to the PWM generator that generates the trigger signal for voltage side inverter.

\section{B. Occurance of Perturbation}

The rating parameters of the system are shown in table. An initial load of $400 \mathrm{KW}$ is connected with the system, at $t=$ $10 \mathrm{sec}$, a step load of $100 \mathrm{KW}$ is added and behavior of the frequency is observed during transient time.

TABLE I. PARAMETERS OF THE SYSTEM

\begin{tabular}{|c|c|c|}
\hline Sr. No. & Parameter & Rating \\
\hline 1 & diesel generator & $300 \mathrm{KW}$ \\
\hline 2 & wind power plant & $200 \mathrm{KW}$ \\
\hline 3 & transformer rating & $500 \mathrm{KVA}$ \\
\hline 4 & frequency & $50 \mathrm{~Hz}$ \\
\hline 5 & $V_{a b c}$ & 380 \\
\hline
\end{tabular}

\section{Virtual Inertia Loop}

In order to meet the contingency of load and generation imbalance, an algorithm is developed based on energy storage system, inverters and control loops called virtual inertia. It plays the role of kinetic energy released in synchronous generator when load-generation miss-match occurs and works as a function of frequency decay and ROCOF. It activates only when frequency deviations occur and becomes inactive when frequency goes back to nominal position $(50 \mathrm{~Hz})$. Wind power plant inverter is operated below its maximum power and some

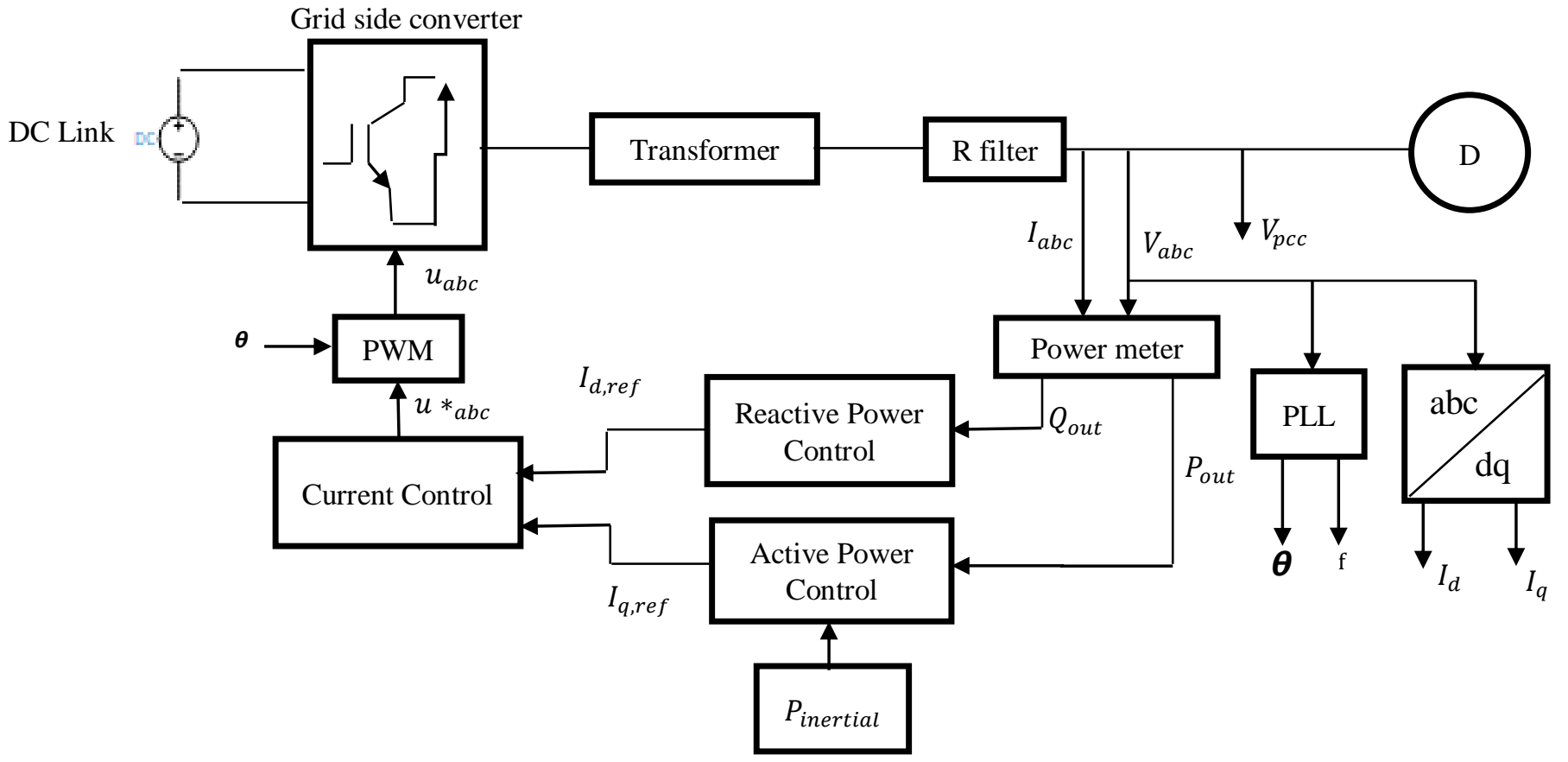

Figure.1 Modeling and control of micro-grid 
power is kept in reserves. Virtual inertia loop is coupled with this reserve power and it activates during transient state when ROCOF occurs. Inverter supplies reserve power to load in proportion to ROCOF and it is calculated as follows:

$$
P_{v s g}=K_{I} \frac{d \Delta \omega}{d t}
$$

Where $P_{v s g}$ is virtual inertia power, $K_{I}$ is inertial constant and $\Delta \omega$ is frequency deviation. The designed virtual inertia loop is shown in figure (2).

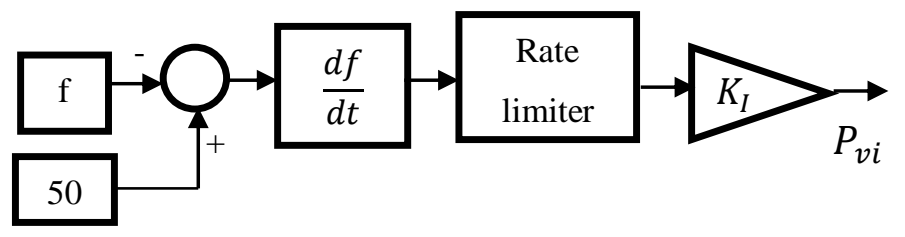

Figure 2. Virtual inertia loop.

\section{RESULTS}

The research work consists of one conventional power plant (synchronous generator) and one RES power plant (wind power plant). The results are discussed the active power flow and frequency deviations with and without virtual inertia emulation.

\section{A. Active Power Flow}

The power generation of wind power plant is shown in figure (3), which is constant $200 \mathrm{KW}$. The power drawn by the load is called the active power of the system. Initially, it is $400 \mathrm{KW}$ and after that $100 \mathrm{KW}$ load is added at $\mathrm{t}=10 \mathrm{sec}$., figure (4) shows the active power of the system.

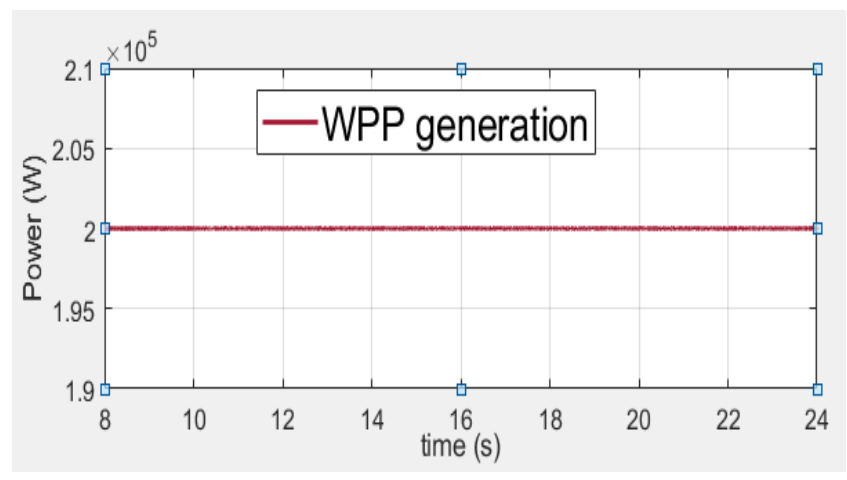

Figure 3. Wind Power Generation

It is cleared from the figure (3) that wind power plant supplies $200 \mathrm{KW}$ power to load and figure(4) shows that load power varies from $400 \mathrm{KW}-500 \mathrm{KW}$. The extra power comes from diesel generator. It supplies $200 \mathrm{KW}$ power initially and $100 K W$ extra power when step load is applied. Figure (5) shows the power production of diesel generator.

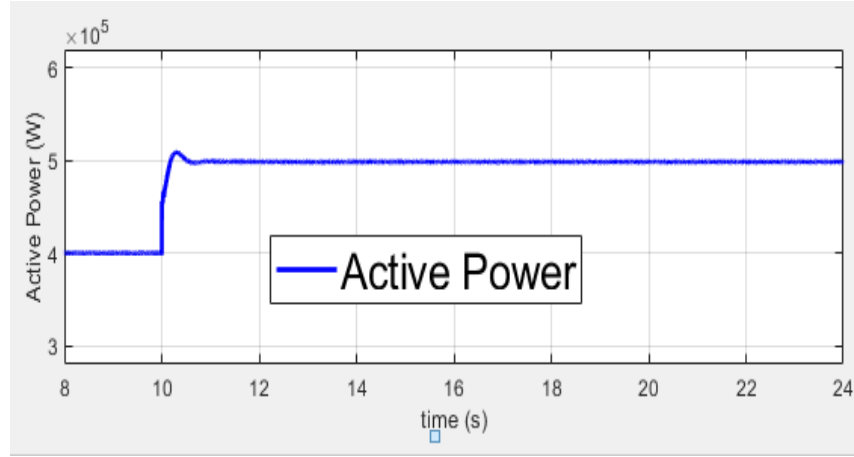

Figure 4. Active Power.

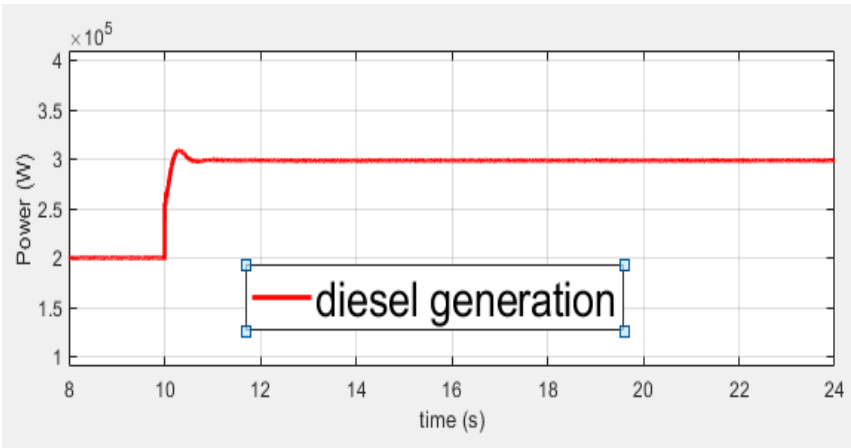

Figure 5. Diesel generation

\section{B. Frequency Behavior}

A frequency dip occurs at $t=10 \mathrm{sec}$ when step load is applied without virtual inertia emulation. Figure (6) shows that frequency deviated from $50 \mathrm{~Hz}$ to $49.28 \mathrm{~Hz}$. Activation of virtual inertial loop provides active power during transient time, catches the ROCOF, and improves the frequency nadir. Figure (7) shows the comparison of frequency with and without the application of virtual inertia loop. It is seen that virtual inertia emulation improves the frequency from $49.28 \mathrm{~Hz}$ to $49.4 \mathrm{~Hz}$. It increases the stability, resiliency and reliability of power system with high penetration of RES and encourages the installation of micro grids.

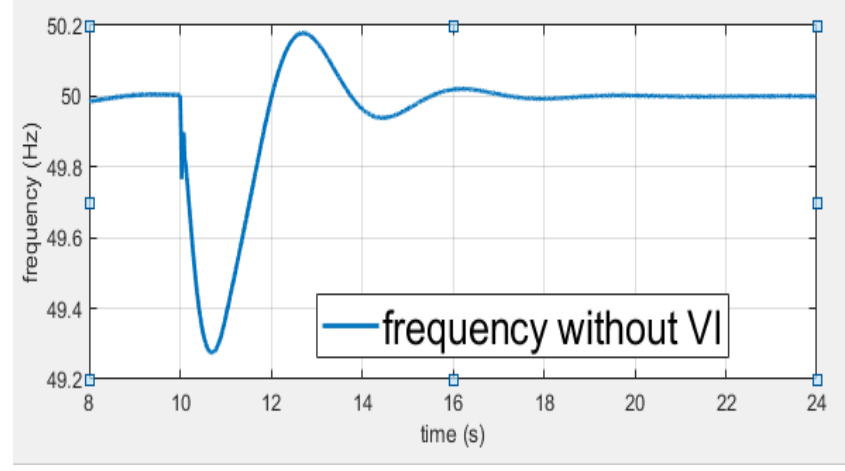

Figure 6. Frequency behavior without virtual inertia 


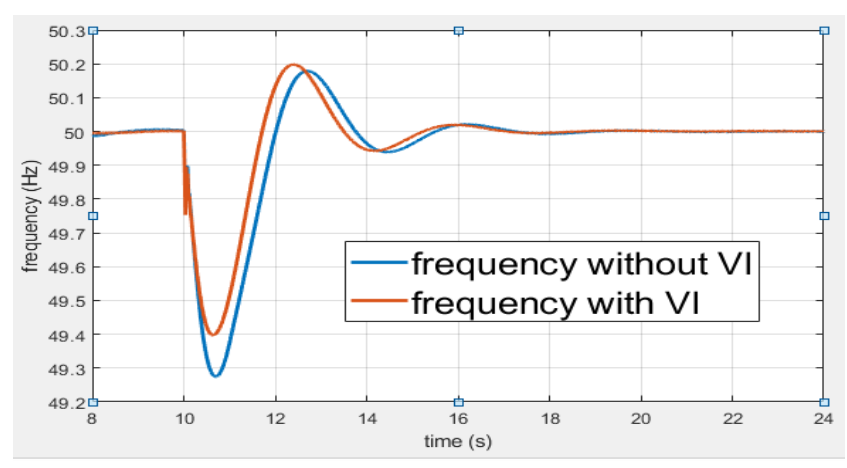

Figure 7. Frequency comparison with and without virtual inertia.

\section{CONCLUSION}

Power system is shifting from large conventional power plants to small DG and RES based generating units. They have small size and posses power electronics technologies. Hence, they have low inertia and consequenlt todays power system is facing frequency stability issues. Virtual inertia emulation is a technique used to improve frequency stability while supplying active power to system during transient time as a replica of kinetic energy in synchronous generator. In this research study, a methodology of virtual inertia emulation is applied on a micro grid having shares of conventional as well as RES. Simulations results confirm that when a contingency is applied in form of step load at $t=10 \mathrm{sec}$, frequency dip occurs during transient time and it may lead to shutdown to some portion of the system. Proposed virtual inertia emulation technique improves this frequency decay, increses the transient frequency stability and ensures the safe operation of the system.

Future work on this area of study can be done by considering virtual damping emulation along with virtual inertia. Consideration of virtual damping can give better performance. Optimal placement of virtual inertia and virtual damping can also be added. Cost analysis and optimization of virtual inertia for designed system needs to be done. A hardware prototype of virtual inertia can be developed and verified.

\section{REFERENCES}

[1] Kerdphol, T., et al., Robust Virtual Inertia Control of a Low Inertia Microgrid Considering Frequency Measurement Effects. IEEE Access, 2019. 7: p. 57550-57560.

[2] Marzband, M., et al., Distributed generation for economic benefit maximization through coalition formation-based game theory concept. International Transactions on Electrical Energy Systems, 2017. 27(6): p. e2313.

[3] Impram, S., S.V. Nese, and B. Oral, Challenges of renewable energy penetration on power system flexibility: A survey. Energy Strategy Reviews, 2020. 31: p. 100539.

[4] Machowski, J., et al., Power system dynamics: stability and control. 2020: John Wiley \& Sons.

[5] Tamrakar, U., et al., Virtual inertia: Current trends and future directions. Applied Sciences, 2017. 7(7): p. 654.

[6] Bryant, M.J., et al., Frequency Control Challenges in Power Systems with High Renewable Power Generation: An Australian Perspective.

[7] Obaid, Z.A., et al., Frequency control of future power systems: reviewing and evaluating challenges and new control methods. Journal of Modern Power Systems and Clean Energy, 2019. 7(1): p. 9-25.
[8] Im, W.-S., et al., Distributed virtual inertia based control of multiple photovoltaic systems in autonomous microgrid. IEEE/CAA Journal of Automatica Sinica, 2016. 4(3): p. 512-519.

[9] Kerdphol, T., et al., Enhanced Virtual Inertia Control Based on Derivative Technique to Emulate Simultaneous Inertia and Damping Properties for Microgrid Frequency Regulation. IEEE Access, 2019. 7: p. 14422-14433.

[10] Ingalalli, A., et al. Modeling Hydro Power System Frequency Dynamics for Virtual Inertia Emulation. in 2019 IEEE 28th International Symposium on Industrial Electronics (ISIE). 2019. IEEE.

[11] Zheng, Y., Virtual Inertia Emulation in islanded microgrids with energy storage system. 2016.

[12] Bevrani, H. and J. Raisch, On virtual inertia application in power grid frequency control. Energy Procedia, 2017. 141: p. 681-688.

[13] Poolla, B.K., S. Bolognani, and F. Dörfler, Optimal placement of virtual inertia in power grids. IEEE Transactions on Automatic Control, 2017. 62(12): p. 6209-6220.

\section{How to cite this article:}

Aehtsham Ul Haq, Iatizaz Ahsan, Shazmina Jamil "Virtual Inertia Emulation in a Hybrid Micro Grid Based on Diesel Generator and Wind Power Plant", International Journal of Engineering Works, Vol. 8, Issue 01, PP. 14-17, January https://doi.org/10.34259/ijew.21.8011417

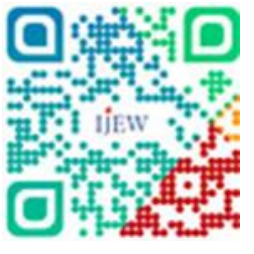

2021 , 